Submission Theme: Efficient and Sustainable Use of Construction Materials

Fifth International Conference on Sustainable Construction Materials and Technologies. http://www.claisse.info/Proceedings.htm

SCMT5

Kingston University London, UK, July 14-17, 2019

\title{
COMPARISON OF INDUSTRIAL AND NATURAL POZZOLANS FOR ASR MITIGATION
}

\author{
Nader Ghafoori Ph. D. ${ }^{1}$, Arash Kian, B.Sc. ${ }^{2}$, Ariful Hasnat, M.Sc. ${ }^{3}$, Stanley Tat, B.Sc ${ }^{2}$ \\ ${ }^{1}$ Professor, Dep. of Civil and Environmental Engineering and Construction, Univ. of Nevada Las \\ Vegas, NV 89154, USA \\ ${ }^{2} \mathrm{MSc}$ student, Department of Civil and Environmental Engineering and Construction, University \\ of Nevada, Las Vegas, NV 89154, USA. \\ ${ }^{3}$ PhD student, Department of Civil and Environmental Engineering and Construction, University \\ of Nevada, Las Vegas, NV 89154, USA.
}

\section{ABSTRACT}

The aim of this study was to compare the effect of industrial and natural pozzolans to mitigate alkali-silica reactivity (ASR). To this end, two sources of reactive aggregates were tested for accelerated mortar bar expansion for eight weeks. Cubes cured in salt water and controlled moisture conditions were tested in compression at 91 days. Type $\mathrm{V}$ cement was replaced at the rates of $15,20,25$, and $30 \%$ by weight. A uniform water to cementitious material ratio of 0.47 was used. The study revealed that a good correlation existed between the cement replacement level by fly ash or natural pozzolan and the ASR-induced expansion. Natural pozzolan outperformed industrial pozzolan at all cement replacement levels. The 91-day compressive strength suffered, in varying degrees due to excessive expansion and cracks.

Keywords: Alkali-silica reactivity, Mortar bar, Aggregate, Fly ash, natural pozzolan, compressive strength.

\section{INTRODUCTION}

Deterioration of concrete structures due to alkali-silica reactivity (ASR) is one of the most common durability problems. The first recorded document on ASR was published in 1919 where laboratory assessment of ASR was conducted using microscopic technique (Sims 1919). In 1940, Stanton (Stanton 1940) pointed out that concrete can suffer deleterious expansion due to the use of reactive aggregates, that most would consider to be the first definitive work on ASR. ASR is the process in which the amorphous silica of aggregate is attacked by hydroxyl ions from concrete's pore solution (Mukhopadhyay et al., 2005). The combined gel type product expands due to tensile forces in the concrete. As a result, concrete cracks, and spalling and other 
deterioration mechanisms occur. A reactive aggregate is mainly responsible for supplying sufficient quantities of reactive silica to form ASR reactions in concrete (Bérubé and Fournier, 1993).

Industrial pozzolan such as fly ash is known to be an effective supplementary cementitious material (SCM) to mitigate ASR in concrete containing reactive aggregates. Use of fly ash has been studied extensively to mitigate ASR, contradictory opinions on its effect can be observed amongst researchers. Turk et al. (2017) found that the reduction of ASR expansion rate due to increase in limestone powder (LSP) content was more prominent compared to the increase of fly ash content in the binary blends system. Kandasamy and Shehata, (2014) concluded that ternary blend of Portland cement didn't offer much advantages over binary blends of Portland cement in ASR mitigation. Thomas et al., (2011) explored the effect of fly ash on ASR in outdoor condition and found that fly ash used at replacement levels of $25 \%$ and $40 \%$ was significantly effective in reducing expansion. Shehata and Thomas, (2000) investigated the effect of different fly ash sources in North America and recommended that chemical composition of the fly ash provides a reasonable indication of its performance in physical expansion tests but cannot be used to accurately predict the degree of expansion or the minimum safe level of fly ash required to suppress expansion to an acceptable limit. Malvar and Lenke (2006) compiled experimental data on ASTM C 1567 and created a chemical index model that can predict the dosage of fly ash necessary to reduce ASR expansion below $0.08 \%$ in mortar bars containing reactive aggregates.

In recent years, due to scarcity of fly ash, alternative pozzolanic materials have been used to mitigate the ASR. Karakurt and Topcu, (2011) investigated the effect of blended cement produced from zeolite (clinoptilolite). Rice husk ash and palm oil fuel ash used by Ramjan et al., (2017) and concluded that, rice husk has adverse effect on concrete expansion while palm fuel ash reduced the expansion rate. However, there remains a research gap on utilizing different types of natural pozzolan to mitigate the ASR induced expansion. This study aimed at the effectiveness of natural volcanic pozzolan on reduction of ASR in comparison to that of the fly ash.

\section{EXPERIMENTAL PROGRAM}

A reactive aggregate collected from a local source was grinded in the machine to reduce the size into ASTM C1260 requirements. ASTM Type V cement was used as a source of main cementing material. Class F fly ash and natural pozzolan substituted a portion of cement at the rate of $15,20,25$, and $30 \%$ by weight. The chemical compositions of cement and pozzolans are given in Table 1. The mixing procedures were conducted in accordance with the ASTM C 305. After $24 \mathrm{~h}$ of moist curing, the bars were demolded, and initial readings were taken before immersing in tap water at $80^{\circ} \mathrm{C}$ for $24 \mathrm{~h}$, after which the zero readings were taken. The test specimens were divided into three equal groups. Each group of specimens was submerged in $\mathrm{NaOH}$ solution in air-tight plastic containers stored in an oven maintaining temperature of $80^{\circ} \mathrm{C}$. Subsequent readings were taken at the age of 3,6,10,14 days, and thereafter one reading per week until the immersion age of 56 days was reached. The 91 days compressive strength of mortar cubes 
cured in salt water solution and in a moisture room were determined in accordance with ASTM C109.

Table 1: Chemical Compositions of Cementitious Materials

\begin{tabular}{lccc}
\hline Component & $\begin{array}{c}\text { Type V Cement } \\
(\%)\end{array}$ & $\begin{array}{c}\text { Class F Fly Ash } \\
(\%)\end{array}$ & $\begin{array}{c}\text { Natural Pozzolans } \\
(\%)\end{array}$ \\
\hline Silicon Dioxide $\left(\mathrm{SiO}_{2}\right)$ & 21 & 59.93 & 68.8 \\
\hline Calcium Oxide $(\mathrm{CaO})$ & 62.4 & 4.67 & 3.2 \\
\hline $\begin{array}{l}\text { Aluminum Oxide } \\
\left(\mathrm{Al}_{2} \mathrm{O}_{3}\right)\end{array}$ & 4 & 22.22 & 8.5 \\
\hline $\begin{array}{l}\text { Ferric Oxide }\left(\mathrm{Fe}_{2} \mathrm{O}_{3}\right) \\
\text { Magnesium Oxide } \\
(\mathrm{MgO}) \text { ) }\end{array}$ & 3.7 & 5.16 & 1.1 \\
\hline Sulfur Trioxide $\left(\mathrm{SO}_{3}\right)$, & 2.6 & - & - \\
\hline $\begin{array}{l}\text { Total Alkali }\left(\mathrm{Na}_{2} \mathrm{O}+\right. \\
\mathrm{K} 2 \mathrm{O})\end{array}$ & 0.54 & 0.38 & - \\
\hline Loss on Ignition $(\mathrm{LOI})$ & 2.0 & 1.29 & 6.4 \\
\hline
\end{tabular}

\section{RESULTS AND DISCUSSION}

\section{Effect of Fly Ash and Natural Pozzolan on Mortar Expansion}

The effect of fly ash replacing different portion of cement as a function of immersion age is presented in Figure 1. No major change was observed up to seven days immersion of the test samples. With the increase of fly ash percentage, ASR expansion reduced significantly up to $20 \%$ by weight of cement replacement. An increase of fly ash beyond $20 \%$ had a minor effect on the reduction of ASR-induced expansion. At 14 days, the $20 \%$ cement replacement resulted in the expansion reduction of 55\% when compared to that of the control mortar. When the immersion age increased to 28 and 56 days, the ASR-induced expansions of the fly ash containing mortars decreased by 47 and $36 \%$ respectively. 


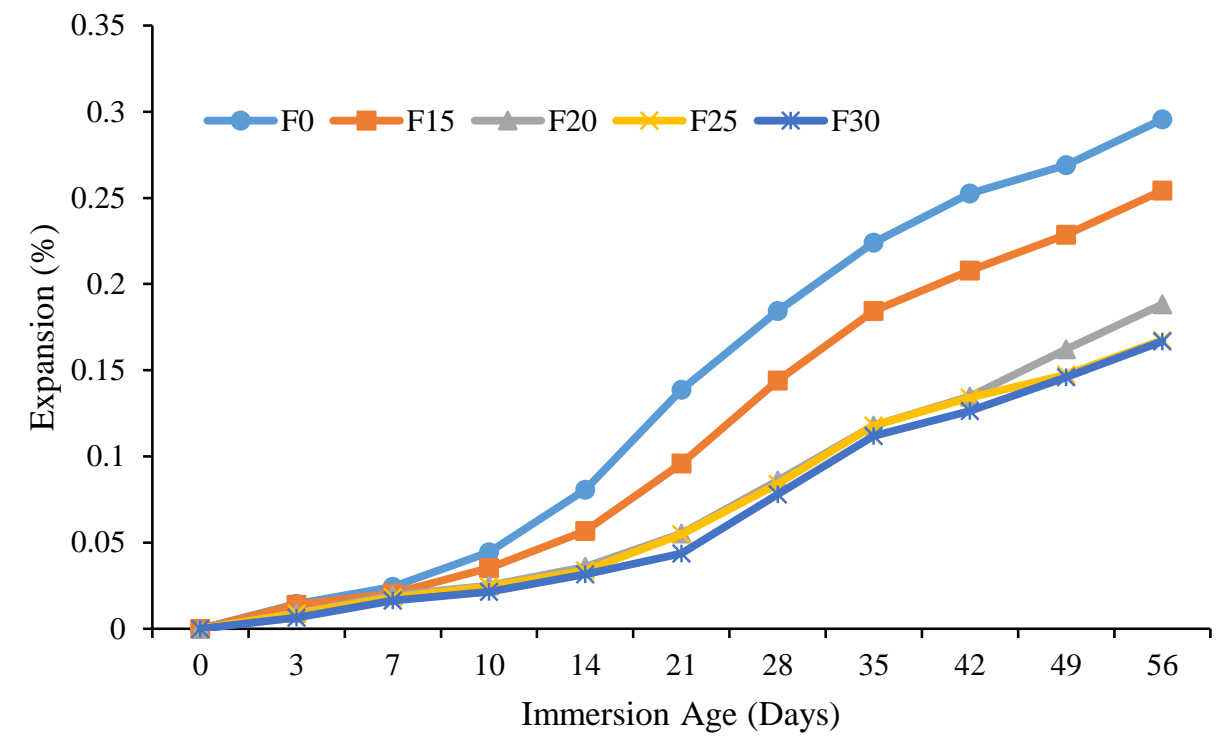

Figure 1: Mortar expansion for different cement replacements by fly ash

The effect of natural pozzolan inclusion as a function of immersion age is presented in Figure 2. As can be seen, inclusion of natural pozzolan reduced expansion at all levels of cement substitution. The reductions of expansion at 14 days were 18, 72, 79 and $85 \%$ for the natural pozzolan containing mortars replacing 15,20, 25 and $30 \%$ by weight of cement, respectively. The ASR-induced expansions decreased averagely by 70 and $52 \%$ at 28 and 56 days, respectively, when natural pozzolan replaced a portion of cement. 


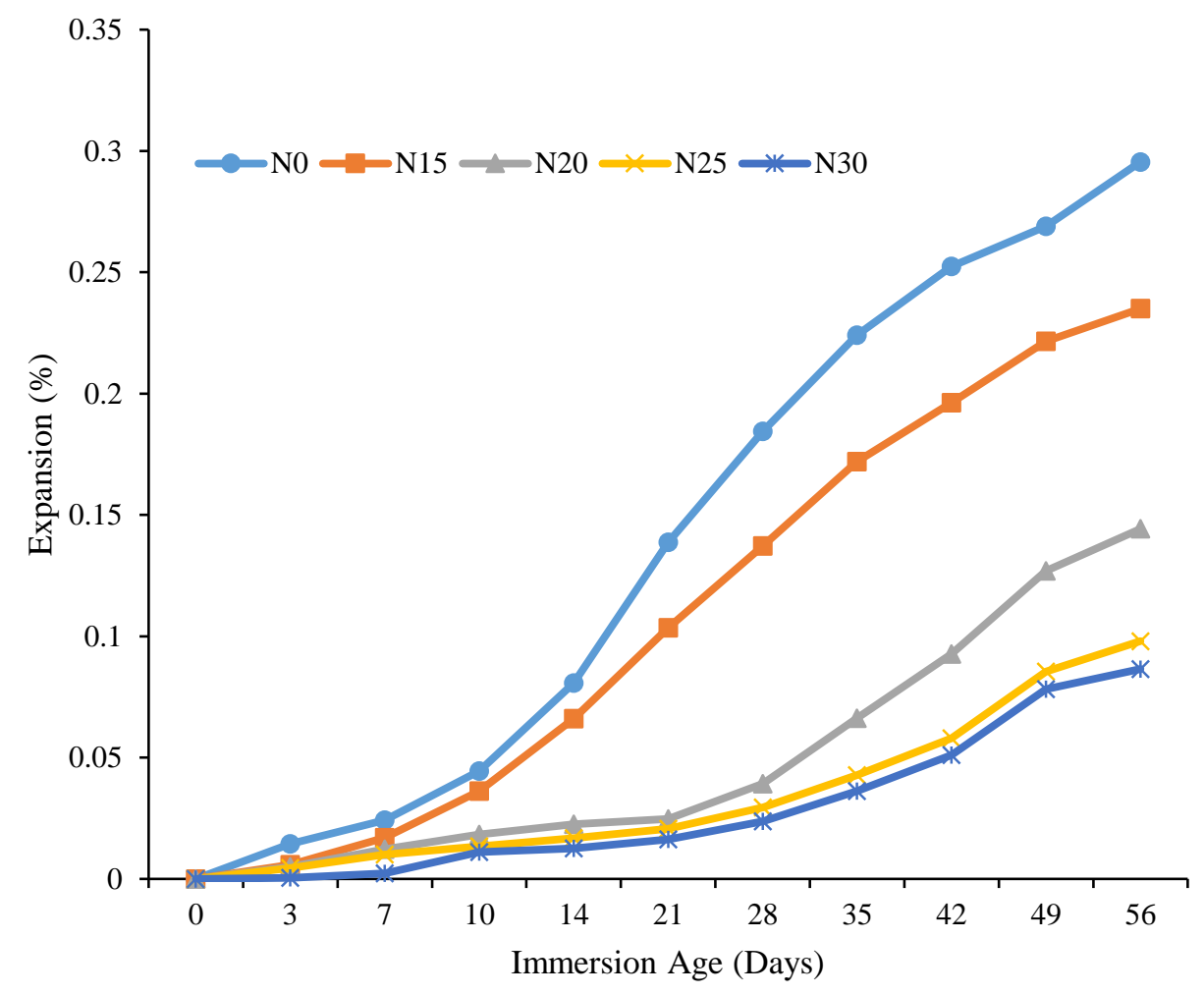

Figure 2: Mortar expansion for different cement replacements by natural pozzolan

\section{Comparison of Industrial and Natural Pozzolans on Mortar Expansion}

Figure 3 presents the effect of the two types of pozzolan at different cement replacement levels. At $15 \%$ by weight replacement of cement, both fly ash and natural pozzolan displayed a similar expansion as shown in Figure 3a. At 20\% replacement level, fly ash containing mortars showed 38, 54 and $23 \%$ higher expansion at 14, 28, and 56 days, respectively, than those of the equivalent mortars containing natural pozzolan (figure $3 \mathrm{~b}$ ). Once the substitution level was extended to $25 \%$, the difference in expansion between the two pozzolan types increased to 50, 65, and $41 \%$ at 14, 28, and 56 immersion age, respectively (figure 3c). At the $30 \%$ cement replacement, natural pozzolan mortar had lower ASR-induced expansion than the fly ash containing mortar by nearly 60,70 , and $48 \%$ at 14,28 , and 56 days, respectively (figure $3 \mathrm{~d}$ ). On average, inclusion of natural pozzolan resulted in the ASR-induced expansion that were 49, 63, and 38\% lower than those of the fly ash containing mortars at the immersion age of 14, 28, and 56 days, respectively. 


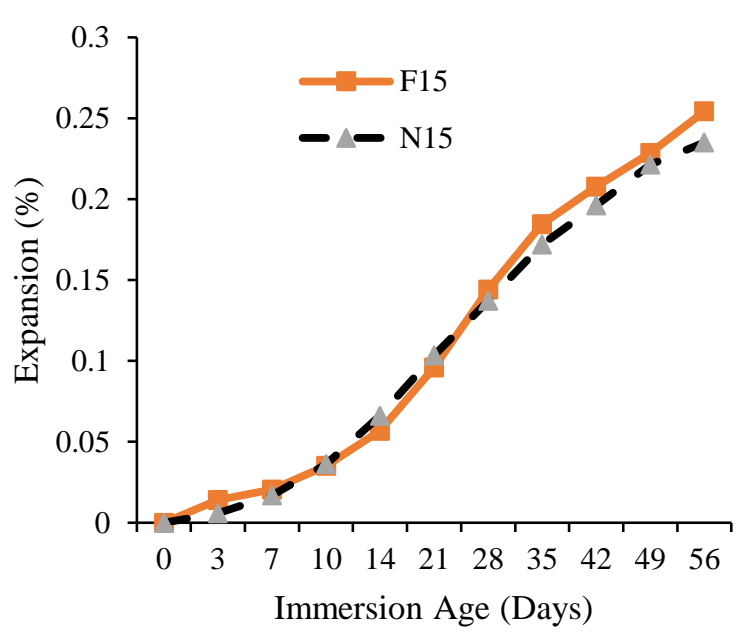

(a)

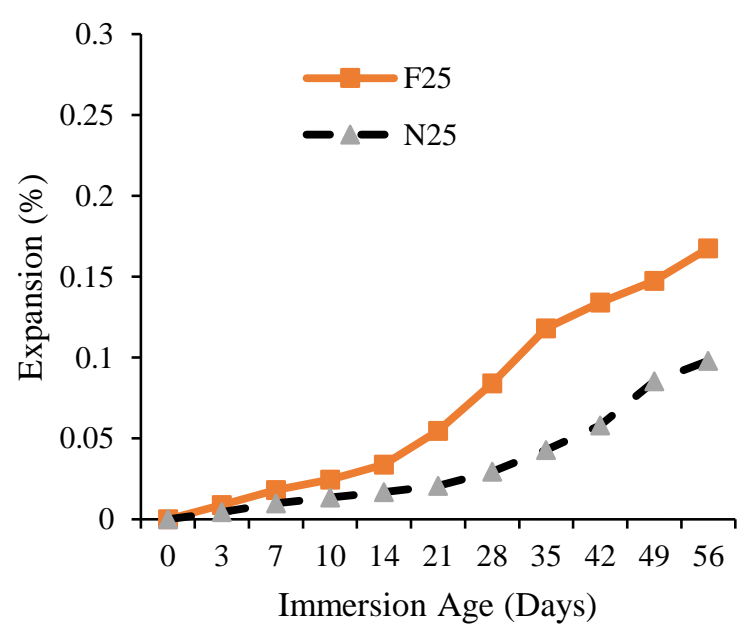

(c)

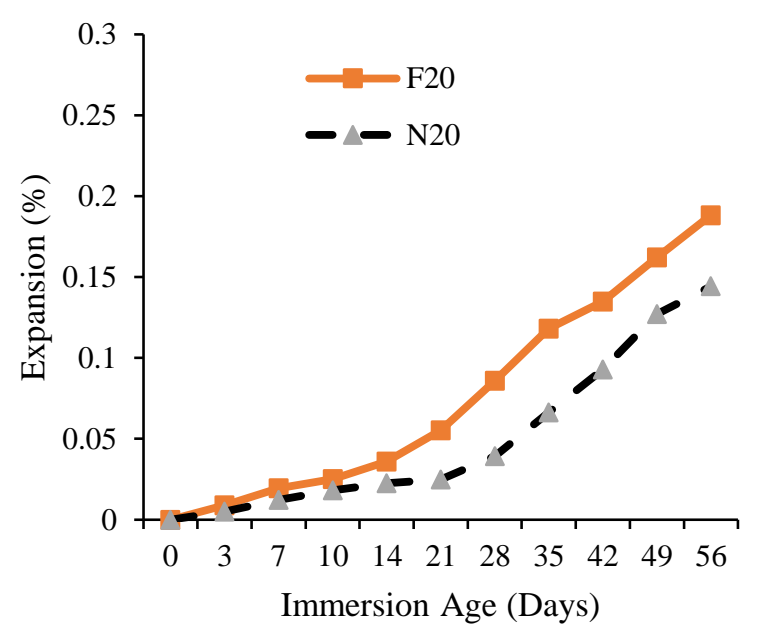

(b)

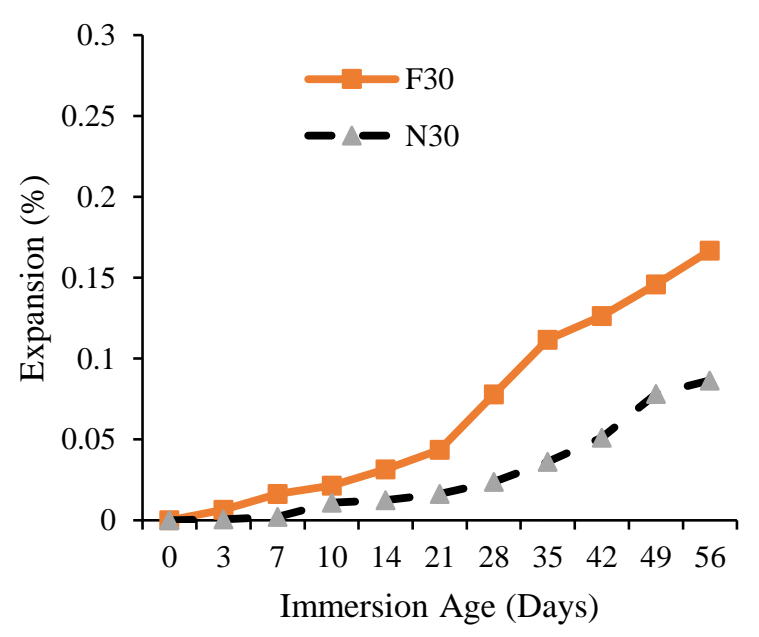

(d)

Figure 3: Effect of pozzolan types on ASR-induced expansion

\section{Compressive Strength}

Figures 4 and 5 present the effect of ASR on compressive strength of mortars made with different percentages of fly ash and natural pozzolan replacing Portland cement. All mixtures cured in salt solution showed lower compressive strength when compared to the moisture-cured samples. The salt immersed control mortar displayed $24 \%$ lower 91- day strength than the equivalent watercured cube. On average, the inclusion of fly ash marginally narrowed the gap between water and salt-cured samples by nearly $16 \%$. The gap between the two immersion types was better bridged by the inclusion of natural pozzolan by approximately $4 \%$, strengthening the conviction on the effectiveness of natural pozzolan, over that of the fly ash, in reduction of alkali-silica reactivity. 


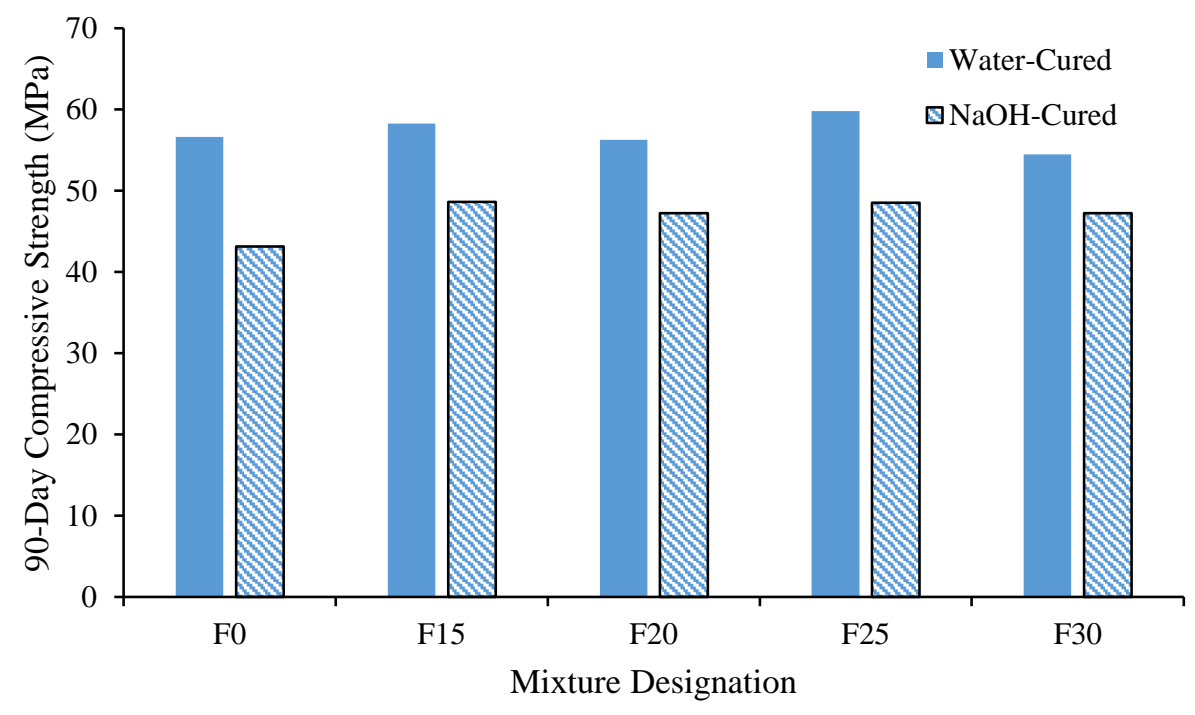

Figure 3: Compressive strength of mortar cube containing fly ash

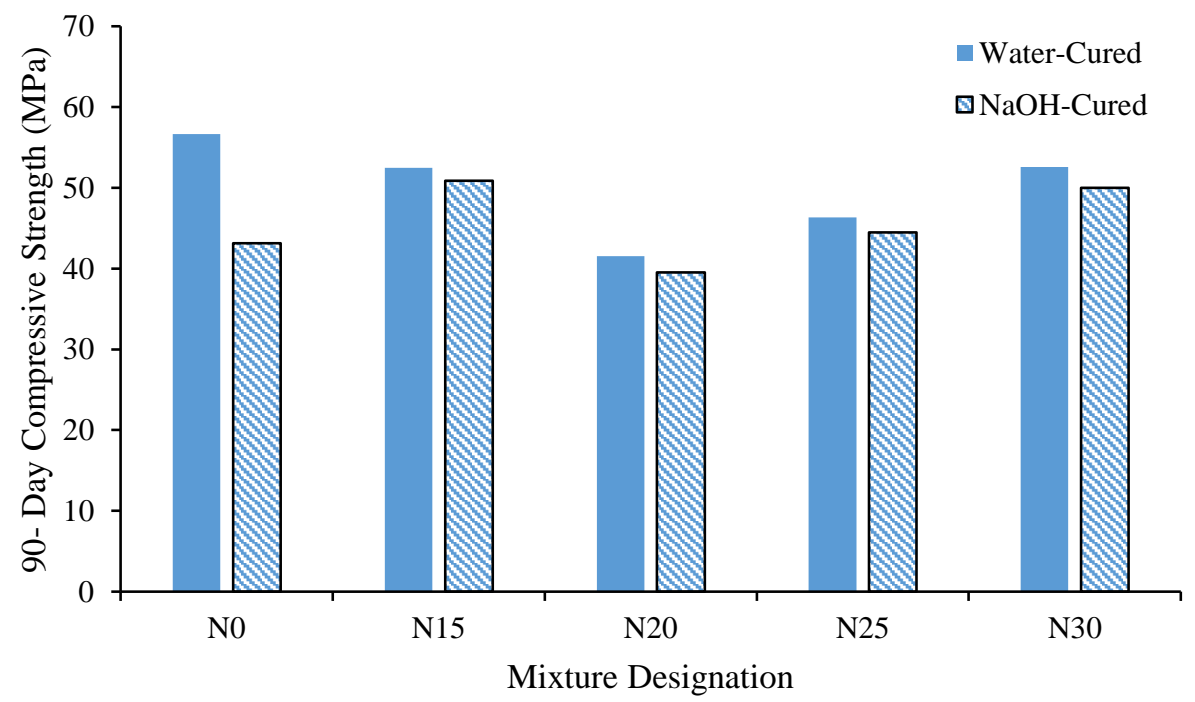

Figure 4: Compressive strength of mortar containing natural pozzolan

\section{CONCLUSION}

The following observations can be drawn from this study:

- Both industrial and natural pozzolans were effective in reducing the ASR-induced expansion. For the natural pozzolan, expansion decreased at all level of cement 
replacements. In the case of industrial pozzolan (class F fly ash), the reduction of expansion beyond $20 \%$ by weight replacement of Portland cement was minimal.

- The studied industrial pozzolan was less effective than the substitution level of Portland cement. natural pozzolan in reducing the expansion at every replacement level.

- The average reduction in compressive strength of studied mortar containing fly ash, due to ASR, was negligible, whereas the 7\% decreased compressive strength of natural pozzolan cube proved be a better alternative than fly ash in mitigation of alkali-silica reactivity.

\section{ACKNOWLEDGEMENT}

This research was funded by a grant made possible by the US Department of Transportation and Nevada Department of Transportation through Solaris Consortium. Thanks are extended to a number of producers who donated materials.

\section{REFERENCES}

ASTM C109 / C109M-16a, Standard Test Method for Compressive Strength of Hydraulic Cement Mortars (Using 2-in. or [50-mm] Cube Specimens), ASTM International, West Conshohocken, PA, 2016, www.astm.org

ASTM C1260-14, Standard Test Method for Potential Alkali Reactivity of Aggregates (MortarBar Method), ASTM International, West Conshohocken, PA, 2014, www.astm.org

ASTM C1567-13, Standard Test Method for Determining the Potential Alkali-Silica Reactivity of Combinations of Cementitious Materials and Aggregate (Accelerated Mortar-Bar Method), ASTM International, West Conshohocken, PA, 2013, www.astm.org.

ASTM C305-14, Standard Practice for Mechanical Mixing of Hydraulic Cement Pastes and Mortars of Plastic Consistency, ASTM International, West Conshohocken, PA, 2014, www.astm.org

Fournier, B., \& Bérubé, M. A. (1993). Recent applications of a modified gel pat test to determine the potential alkali-silica reactivity of carbonate aggregates. Cement and Concrete Composites, 15(1-2), 49-73.

Kandasamy, S., \& Shehata, M. H. (2014). The capacity of ternary blends containing slag and high-calcium fly ash to mitigate alkali silica reaction. Cement and Concrete Composites, 49, 92-99. 
Karakurt, C., \& Topçu, İ. B. (2011). Effect of blended cements produced with natural zeolite and industrial by-products on alkali-silica reaction and sulfate resistance of concrete. Construction and Building Materials, 25(4), 1789-1795.

Malvar, L. J., \& Lenke, L. R. (2006). Efficiency of fly ash in mitigating alkali-silica reaction based on chemical composition. ACI materials journal, 103(5), 319-325.

Mukhopadhyay, A., Zollinger, D., \& Shon, C. S. (2005). Evaluation of alkali silica reactivity of mineral and aggregate using dilatometer method. Innovative Pavement Research Foundation. Report IPRF-01-G-002-02-5.1.

Ramjan, S., Tangchirapat, W., \& Jaturapitakkul, C. (2018). Effects of Binary and Ternary Blended Cements Made from Palm Oil Fuel Ash and Rice Husk Ash on Alkali-Silica Reaction of Mortar. Arabian Journal for Science and Engineering, 43(4), 1941-1954.

Shehata, M. H., \& Thomas, M. D. (2000). The effect of fly ash composition on the expansion of concrete due to alkali-silica reaction. Cement and Concrete Research, 30(7), 1063-1072.

Sims, IN. (1919). The assessment of concrete for ASR. Concrete, 26(2), 42-48.

Stanton, T. E. (1940). Expansion of concrete through reaction between cement and aggregate. ASCE Eng.,107(1), 157-164.

Thomas, M., Dunster, A., Nixon, P., \& Blackwell, B. (2011). Effect of fly ash on the expansion of concrete due to alkali-silica reaction-Exposure site studies. Cement and Concrete composites, 33(3), 359-367.

Turk, K., Kina, C., \& Bagdiken, M. (2017). Use of binary and ternary cementitious blends of FClass fly-ash and limestone powder to mitigate alkali-silica reaction risk. Construction and Building Materials, 151, 422-427. 